ARTICLE

\title{
The first Australian plant foods at Madjedbebe, $65,000-53,000$ years ago
}

\author{
S. Anna Florin (1) ${ }^{1 凶}$, Andrew S. Fairbairn ${ }^{1,2,3}$, May Nango ${ }^{4}$, Djaykuk Djandjomerr ${ }^{4}$, Ben Marwick ${ }^{5}$, \\ Richard Fullagar (iD ${ }^{6}$, Mike Smith (10 ${ }^{7,8}$, Lynley A. Wallis ${ }^{9,10}$ \& Chris Clarkson (iD) $1,2,3 \times$
}

There is little evidence for the role of plant foods in the dispersal of early modern humans into new habitats globally. Researchers have hypothesised that early movements of human populations through Island Southeast Asia and into Sahul were driven by the lure of highcalorie, low-handling-cost foods, and that the use of plant foods requiring processing was not common in Sahul until the Holocene. Here we present the analysis of charred plant food remains from Madjedbebe rockshelter in northern Australia, dated to between $65 \mathrm{kya}$ and 53 kya. We demonstrate that Australia's earliest known human population exploited a range of plant foods, including those requiring processing. Our finds predate existing evidence for such subsistence practices in Sahul by at least 23ky. These results suggest that dietary breadth underpinned the success of early modern human populations in this region, with the expenditure of labour on the processing of plants guaranteeing reliable access to nutrients in new environments.

\footnotetext{
${ }^{1}$ School of Social Science, University of Queensland, Brisbane, QLD 4072, Australia. ${ }^{2}$ Australian Research Council Centre of Excellence for Australian Biodiversity and Heritage, University of Wollongong, Wollongong, NSW 2522, Australia. ${ }^{3}$ Depatrment of Archaeology, Max Planck Institute for the Science of Human History, Kahlaiche Strasse 10, 07745 Jena, Germany. ${ }^{4}$ Gundjeihmi Aboriginal Corporation, 5 Gregory Place, Jabiru, NT 0886, Australia.

${ }^{5}$ Department of Anthropology, University of Washington, Seattle, WA 98195, USA. ${ }^{6}$ Centre for Archaeological Science, School of Earth, Atmospheric and Life Sciences, University of Wollongong, Wollongong, NSW 2522, Australia. ${ }^{7}$ College of Humanities, Arts and Social Sciences, Flinders University, Adelaide, SA 5042, Australia. ${ }^{8}$ Centre for Historical Research, National Museum of Australia, Canberra, ACT 2601, Australia. ${ }^{9}$ Nulungu Research Institute, University of Notre Dame Australia, Broome, WA 6725, Australia. ${ }^{10}$ Present address: Griffith Centre for Social and Cultural Research, Griffith University, Brisbane, QLD

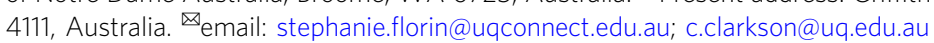


T he role of plant foods in the evolution and dispersal of early modern humans (EMHs) has often been underestimated. A long-held focus on the notion of Paleolithic populations as meat eaters and a lack of consistent archaeobotanical recovery has frequently constrained analysis and understandings of EMH diet to its animal components ${ }^{1}$. Extensive use and processing of plant resources, and an associated broadening of the diet, was therefore typically considered a late Pleistocene/early Holocene phenomenon, linked to changing foraging behaviours in the millennia prior to the emergence of agriculture $^{2,3}$. However, while plant foods may not make up the dominant proportion of EMH diets globally, more recent research into plant macro- and micro-fossils is breaking down this paradigm: the use of plant foods, including those associated with later agricultural transitions, such as grass seeds and underground storage organs (USOs), is now evidenced in Middle Stone Age sites in Africa and the Middle East ${ }^{4-7}$; the processing of toxic plants (Dioscorea hispida and Pangium edule) is now dated to as early as 46-34 kya in Niah Cave, Borneo ${ }^{8-10}$; the translocation of yams (Dioscorea spp.) to high altitudes and management of monodrupe pandanus stands, facilitated early use of highland environments in New Guinea $(\sim 49 \mathrm{kya})^{11,12}$; and associated plant-processing technologies, such as seed-grinding stones, are linked to EMH dispersal into northern Australia ${ }^{13}$.

This shift in paradigm is particularly important when considering the southern dispersal of Homo sapiens out of Africa. Key debates in this region have focused on both the 'modernity' of EMH populations involved in these migrations ${ }^{14,15}$ and the 'pathways' they may have followed ${ }^{16}$. Proponents of the single coastal dispersal model suggest human populations expanded along coastal environments $\sim 60$ kya, moving quickly through Sunda and Wallacea, and into Sahul ${ }^{17,18}$. This model emphasises the lure of high-ranked coastal resources and suggests diet breadth was likely narrow in the earliest phases of human expansion throughout this region. In contrast, other models highlight early adaptations to non-coastal environments by EMHs leaving Africa $16,19,20$, including to more extreme ecosystems (e.g. rainforests ${ }^{8-10,21,22}$, high-altitudes ${ }^{11,12}$ and deserts ${ }^{23,24}$ ). Current evidence for Pleistocene plant use in Sunda and Sahul, while not necessarily related to the earliest phases of human expansion in this region ${ }^{18}$, largely supports this latter interpretation. This is because the intensive and multi-step processing techniques required to make the identified plant foods edible are indicative of both complex and flexible foraging, and the kind of broad diet that underpins adaptations to more difficult environments ${ }^{1,25}$.

Here we report on the charred plant macrofossils recovered from the earliest layer of dense occupation at Madjedbebe. Madjedbebe is a rockshelter in western Arnhem Land (northern Australia) situated at the base of the Djuwamba Massif, an escarpment outlier to the east of the Magela Creek floodplain (Fig. 1). Its earliest, dense phase of occupation (Phase 2) contains charcoal, abundant ground ochre, grinding stones, including those used for seed-grinding, and a dense assemblage of unique flaked stone artefact types and raw materials $(>10,000$ artefacts). This phase is dated to c.65-53 kya on the basis of an extensive single-grain optically stimulated luminescence and

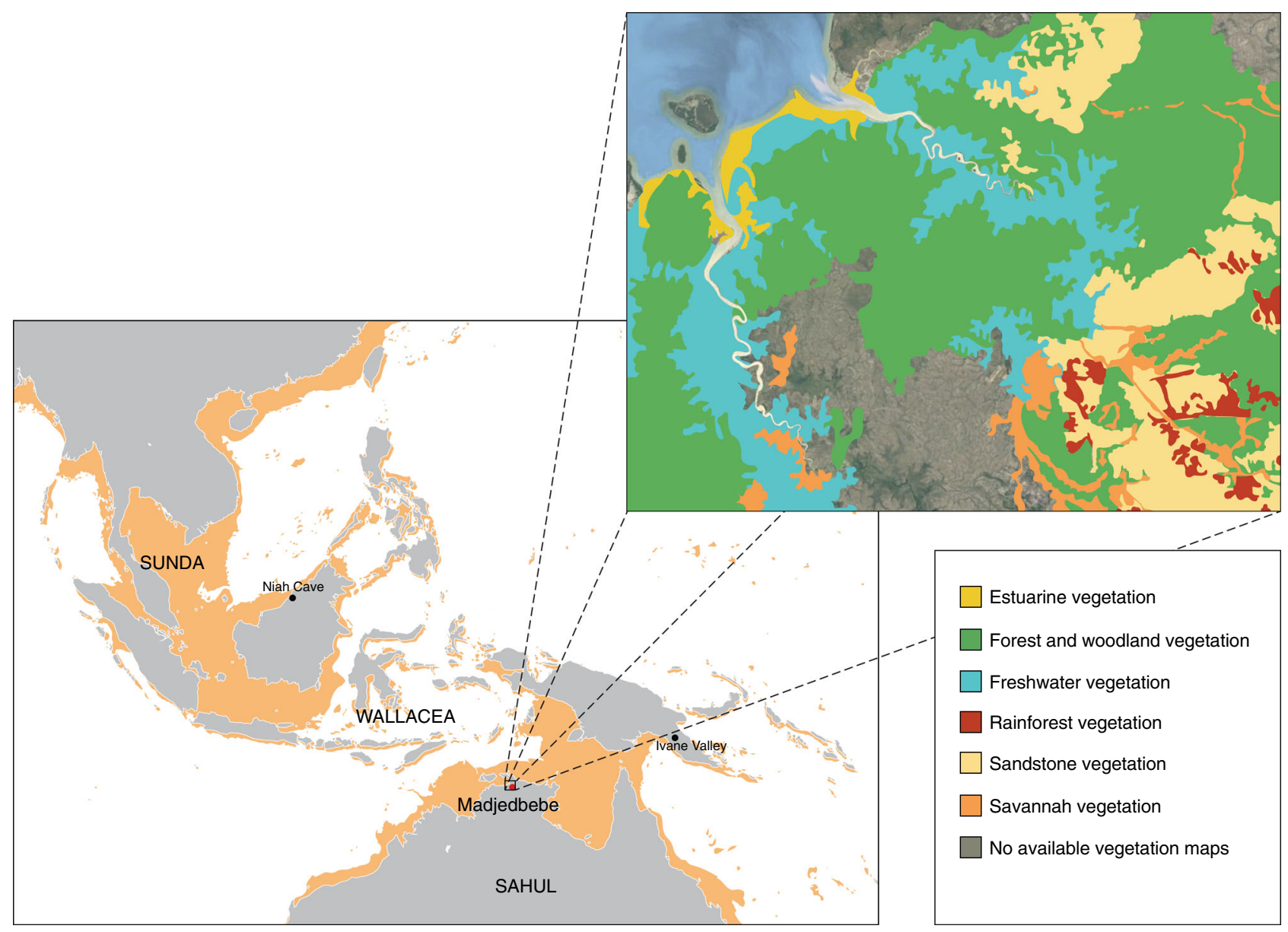

Fig. 1 Site location. a Regional map showing the location of Madjedbebe, and other sites mentioned in-text, adapted from Norman et al. 201847; b current distribution of vegetation communities in proximity to Madjedbebe, developed from map data provided by Google, Landsat/Copernicus, TerraMetrics, and vegetation maps of the Adelaide and Alligator Rivers area 48,49 . 
accelerator mass spectrometry radiocarbon dating regime (Supplementary Fig. 1) 13,26,27. The archaeobotanical assemblage from Phase 2, therefore, provides the earliest known evidence for an EMH diet in Sahul. We demonstrate that Australia's earliest known human population exploited a range of plant foods, including some requiring processing. Our findings have implications for understanding EMH behavior, cognitive flexibility and subsistence strategies at the eastern end of the modern human dispersal arc.

\section{Results}

Phase 2 plant macrofossil assemblage. Plant macrofossil remains were recovered from all phases of occupation at the site using flotation (see Methods). The Phase 2 assemblage includes over 1000 non-wood plant macrofossils from a distinct hearth feature $(\mathrm{C} 1 / 43 \mathrm{~A})$ and excavated sediment matrix (see Supplementary Table 1). These macrofossils can be broadly categorised into four distinct groups: (i) endocarp and mesocarp ('nutshell' or 'fruitstone') from a variety of fruit and nut producing species; (ii) vegetative parenchyma from USOs ('roots and tubers'); (iii) stem tissue from the Arecaceae (palm) family and (iv) various other fragments of plant material. Within these groups, genus-, or species-specific identifications have been made for five taxa, with a further five types identified to broader botanical categories.

The paucity of charcoal prior to human occupation (Supplementary Fig. 2a) and the presence of a diversity of edible species preserved by burning suggests that the assemblage was largely derived from human activities, specifically the cooking and disposal of plant resources in hearths. This is corroborated by the relatively high percentage $(17 \%)$ of fragile parenchymatous tissue from USOs preserved in the assemblage. USO-producing species have evolved to survive and profit from bushfires, rapidly regenerating new aerial shoots from their buried vegetative organs ${ }^{28}$. These organs, themselves, are therefore unlikely to have been charred within the site without human activity. However, this does not preclude the inclusion of some of the Phase 2 plant macrofossils via non-human agents.

Endocarp and mesocarp. Charred endocarps of five fruit and nut taxa were identified: Buchanania sp.; Canarium australianum; polydrupe Pandanus sp.; Persoonia falcata; and Terminalia sp. (Fig. 2). All of these taxa are common in open forest and woodland, and/or monsoon vine forest environments ${ }^{29}$, and the majority require little or no processing. Today, the abundant and easily harvested 'plums' of Buchanania spp. and Persoonia falcata are highly sought after. The fruits can be eaten raw but are also often ground into a paste, incorporating the endocarp and seed, prior to consumption (MN, DjDj). Canarium australianum is a relative of the widely used Melanesian tree-crop, galip (C. indicum), and has a small oil-rich kernel $(<1 \mathrm{~cm})$ that is easily extracted with a single blow from a hammerstone (DjDj). A number of Terminalia species are edible, consumed either as fruits ( $T$. carpentariae, T. erythrocarpa, T. ferdinandiana, T. microcarpa) or easily-extracted nuts (T. grandiflora; $\mathrm{MN}, \mathrm{DjDj})^{30}$. However, there are also a number of non-edible species of Terminalia in the Northern Territory.

Pandanus formed a substantial element of the early colonial diet of Indigenous Australians in Arnhem Land and is also a valuable material in weaving and fibrecraft ${ }^{31}$. There are two types of polydrupe pandanus in Arnhem Land: $P$. spiralis and $P$. basedowi ${ }^{29}$. Only one fragment from Phase 2 at Madjedbebe, a portion of mesocarp, can be securely identified as P. spiralis (Fig. 3f). However, it is likely that the majority come from this species, since $P$. basedowii only grow on the escarpment top and would have been difficult to access from Madjedbebe (see Fig. 1b). Extracting kernels from the fibrous and mechanically-resistant prismatic structure of the $P$. spiralis drupe is a labour-intensive process when using stone tools. The explorer, Ludwig Leichardt, recorded Indigenous groups in the Gulf of Carpentaria in the 1840s using "large flat stones and pebbles" to bash apart the drupes ${ }^{32}$. However, once open, the small kernels are rich in fat $(44-50 \%)$ and protein $(20-34 \%)^{33}$.

Vegetative parenchyma. Three distinct types of vegetative parenchyma are present in the Phase 2 assemblage. These include parenchymatous tissue from two types of monocotyledonous, stem-based storage organs and a fragment from a secondary-root storage organ (Fig. 3). Monocotyledonous stem-based storage organ Type A is represented in Phase 2 only by charred fragments of its skin tissue, which have distinct root abscission scars, or 'eyes', and surface patterning (Fig. 3a, b). These fragments are comparable to charred peelings generated by contemporary Indigenous Australians when they remove the coarse external surface of cooked USOs before consumption, often in proximity to the hearth in which they were cooked (MN, DjDj; Fig. 3d). The presence of an endodermis, in a larger fragment of this type recovered from Phase 3 , allows for its further identification as an aquatic or semi-aquatic USO (Fig. 3c). Endodermis is rarely present in stem tissue, except in aquatic plants where they are significant in controlling water balance within perennating stems ${ }^{34}$.

Arecaceae. There are two types of Arecaceae stem tissue present in the Phase 2 assemblage (Fig. 4). Type A, characterised by the presence of mostly two or more metaxylem elements per fibrovascular bundle, has a similar anatomy to that of Livistona spp. palm tissue. Type B, represented largely by the peripheral section of the palm stem, is characterised by the presence of only one metaxylem element per fibrovascular bundle. Type B is only found in the Phase 2 assemblage and may represent the peripheral xylem of Type A or another taxon of the Arecaceae. The apex, or 'heart', and pith, or whole young stem, of several palms present in open woodland and monsoon vine forest environments in western Arnhem Land can be consumed (apex: Carpentaria acuminata, Hydriastele ramsayi; apex and pith: L. benthamii, $L$. humilis and L. inermis) $)^{30,35}$. While the apex of these palms may be eaten raw or lightly roasted, the pith requires roasting for an extended period $(\sim 12 \mathrm{~h})$ prior to pounding. This process removes the most fibrous elements from the otherwise starchy pith, making the carbohydrates within the pith readily available for consumption. While there are no distinguishing apical features on the fragments of stem from the Phase 2 assemblage, their size makes it impossible to securely identify them as basal (pith) stem.

\section{Discussion}

In summary, the plant macrofossil assemblage from Phase 2 provides evidence for the consumption of a range of plant foods $(\sim 10)$ by the EMH population occupying Madjedbebe from 65-53 kya. These plant foods were foraged from open forest and woodland, and, to a lesser extent, monsoon vine forest, and aquatic environments, all of which were likely in proximity to the site during this phase ${ }^{13}$. These plant foods provided a variety of dietary macronutrients, comprising carbohydrates (USOs, palm stems and fruits), fats and proteins (pandanus kernels and other tree nuts). Some of these plant foods, such as the fruits and easilyextracted nuts, represent readily available, high-ranked resources. However, other plant foods present in the assemblage required varying levels of processing prior to consumption. This included the cooking (and peeling) of USOs and palm stems, likely the further pounding of palm pith, and the laborious extraction of Pandanus spiralis kernels. Furthermore, while there were no edible seeds recovered in the plant macrofossil assemblage, residue and usewear evidence from the Phase 2 grinding stone 

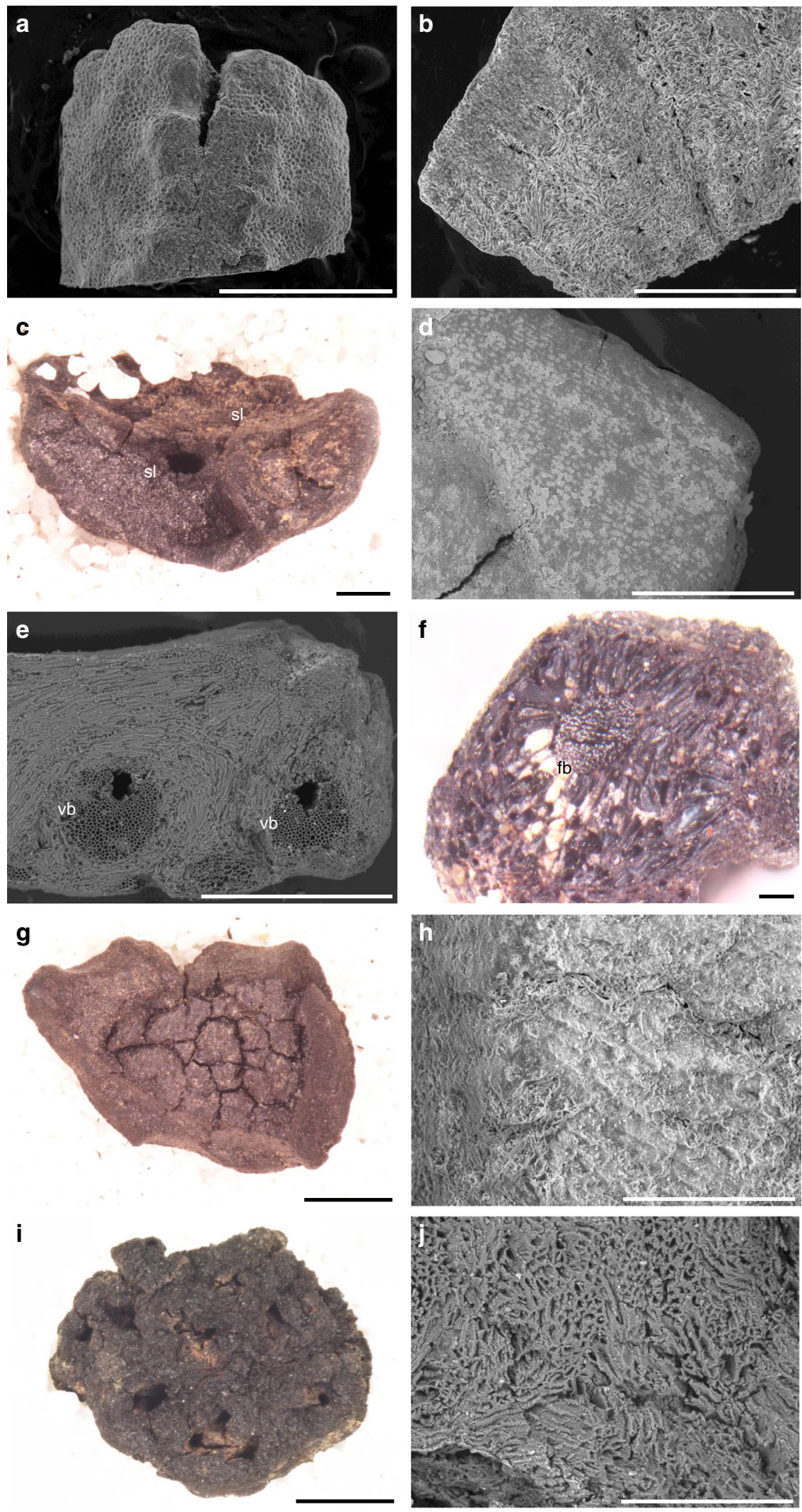

Fig. 2 Examples of endocarp from Phase 2. a, b Buchanania sp. endocarp from C2/46(HR), a scale bar is $1 \mathrm{~mm}$, b transverse section, scale bar is 500 um; c Canarium australianum endocarp from C2/38(HR), scale bar is $500 \mu \mathrm{m}$; d C. australianum endocarp from C2/37(HR), close-up of internal surface, scale bar is $500 \mu \mathrm{m}$; e Polydrupe Pandanus sp. endocarp from C2/42(HR), transverse section, scale bar is $500 \mu \mathrm{m}$; $\mathbf{f} P$. spiralis mesocarp from C2/37, scale bar is $200 \mu \mathrm{m} ; \mathbf{g}, \mathbf{h}$ Persoonia falcata endocarp from C2/37(HR), $\mathbf{g}$ scale bar is $1 \mathrm{~mm}, \mathbf{h}$ close-up of internal surface, scale bar is $200 \mu \mathrm{m} ; \mathbf{i}, \mathbf{j}$ Terminalia sp. endocarp from C2/37(HR), i scale bar is $1 \mathrm{~mm}, \mathbf{j}$ transverse section, scale bar is $200 \mu \mathrm{m}$. See the supporting online information and Supplementary Figs. 3-7 for detailed identification proofs and the corresponding reference materials. sl seed locule, vb vascular bundle, fb fibrous bundle. 

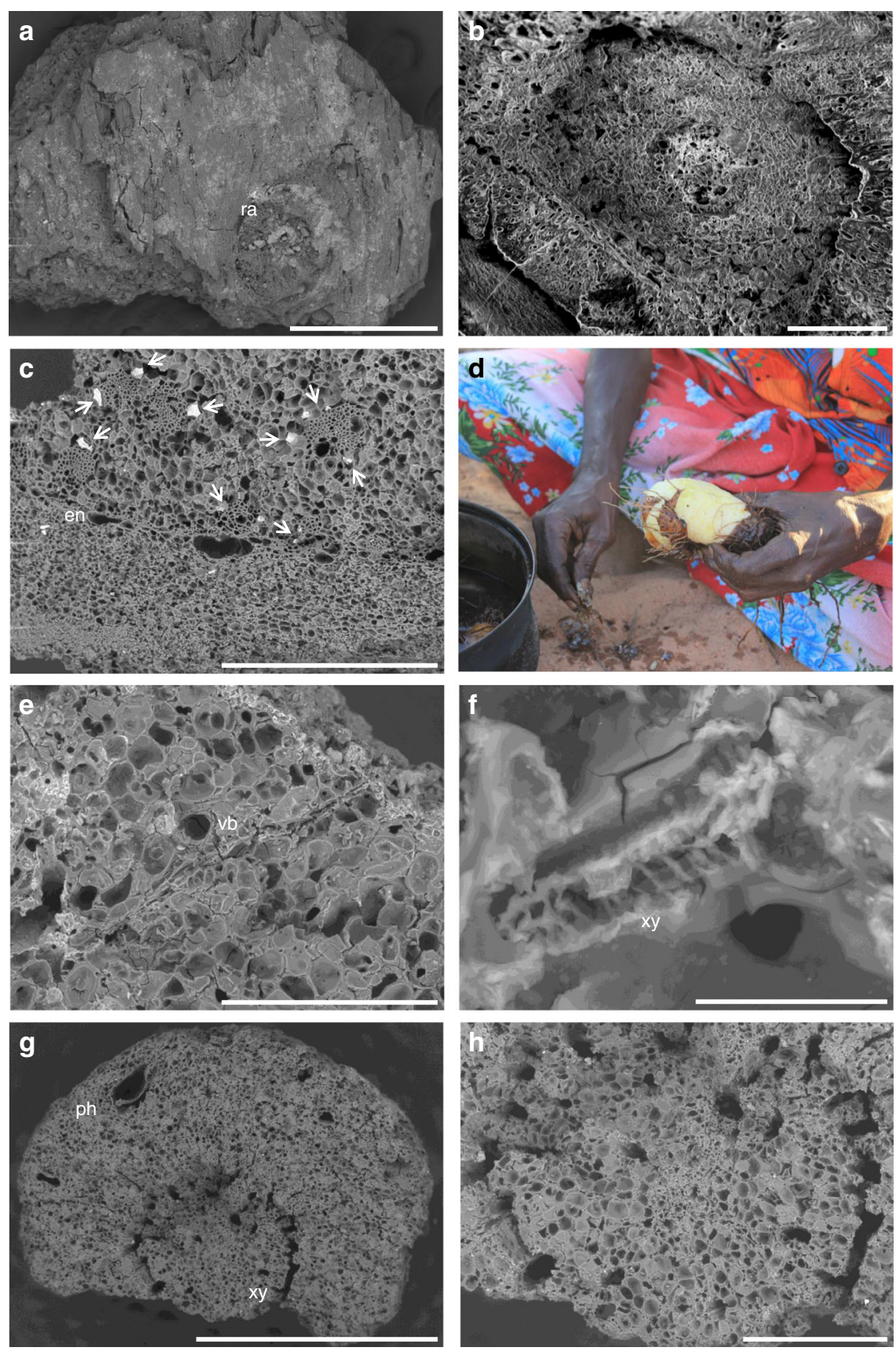

Fig. 3 Examples of vegetative parenchyma from Phase 2. a, b Monocotyledonous stem-based storage organ Type A from C2/41; a depicting skinpatterning and root abscission scar, scale bar is $500 \mu \mathrm{m} ; \mathbf{b}$ close-up of root abscission scar, scale bar is $100 \mu \mathrm{m}$; $\mathbf{c}$ transverse section of monocotyledonous stem-based storage organ Type A from C2/32 A, depicting an endodermis and a series of closed collateral vascular bundles, arrows point to phytoliths on edges of vascular bundles, scale bar is $500 \mu \mathrm{m}$; d MN peeling a 'hairy' Dioscorea bulbifera tuber beside a hearth built to cook it, photo taken by SAF; e, $\mathbf{f}$ longitudinal section of monocotyledonous stem-based storage organ Type B; e scale bar is $300 \mu \mathrm{m}$; $\mathbf{f}$ close-up of vascular bundle, scale bar is $20 \mu \mathrm{m}$; $\mathbf{g}$, $\mathbf{h}$ transverse section of secondary-root storage organ Type A from C2/39 A; $\mathbf{g}$ scale bar is $2 \mathrm{~mm}$; $\mathbf{h}$ close-up of central tract of xylem, scale bar is $500 \mu \mathrm{m}$. ra root abscission scar, en endodermis, vb vascular bundle, ph phloem, xy xylem.

assemblage has identified seed-grinding during this initial phase of occupation ${ }^{13}$. While none of these plants are toxic, the processing required to extract and make edible the nutritious components from some of the taxa present is suggestive of multi-step and labour-intensive processing techniques.

These findings, which predate existing evidence for the processing of plant foods in Sahul by at least $23 \mathrm{ky}^{36,37}$, suggest that a broader range of lower ranked plant foods was consumed during early occupation of Sahul than envisaged by proponents of the single coastal dispersal model ${ }^{17,18}$. This does not negate the possibility that EMH populations first entered Sahul exploiting high-ranked, coastal resources found on its now-submerged coastline. However, the investment of labour and technology into the extraction and processing of fruits, nuts, USOs and likely seeds at Madjedbebe 65-53 kya, does suggest that a broad diet was part of the toolkit employed by the EMH populations who reached Sahul.

Indeed, as EMH populations crossed the Wallace Line, novel fauna would likely have caused significant disruptions to their hunting strategies. However, many of the families, and in some 

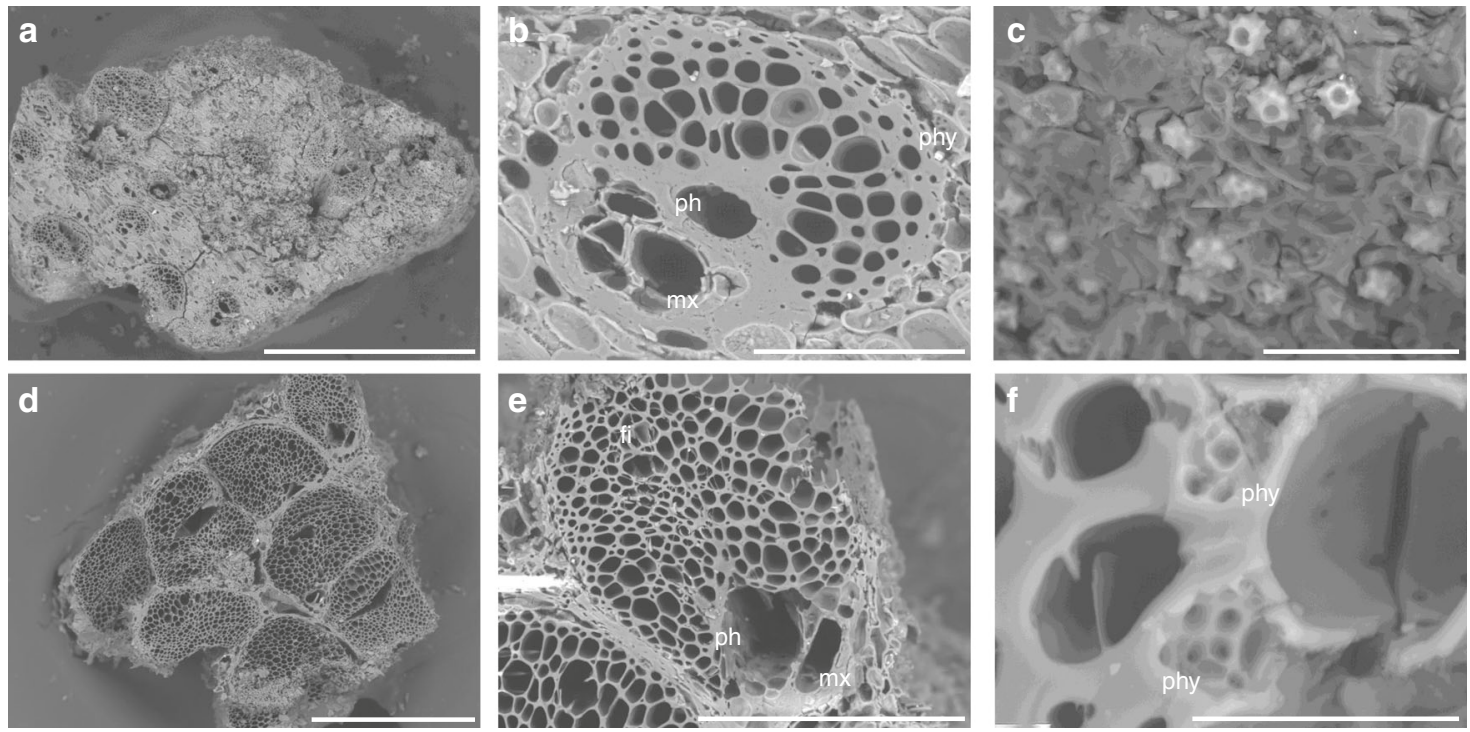

Fig. 4 Examples of Arecaeae family stem tissue from Phase 2. a-c Transverse section of Arecaceae stem Type A (cf. Livistona spp.) from C2/44, a scale bar is $1 \mathrm{~mm}, \mathbf{b}$ close-up of fibrovascular bundle, scale bar is $100 \mu \mathrm{m}, \mathbf{c}$ close-up of globular echinate phytoliths, scale bar is $30 \mu \mathrm{m}$; $\mathbf{d}, \mathbf{f}$ transverse section of Arecaceae stem Type B from C2/44, d scale bar is $500 \mu \mathrm{m}$, e close-up of fibrovascular bundle, scale bar is $200 \mu \mathrm{m}$; $\mathbf{f}$ transverse section of Arecaceae stem Type B from C2/45, close-up of globular echinate phytoliths, scale bar is $20 \mu \mathrm{m}$. See the supporting online information and Supplementary Fig. 8 for a detailed identification proof of Arecaceae stem Type A (cf. Livistona spp.) and the corresponding reference material. ph phloem, mx metaxylem, phy phytolith.

cases genera (including Buchanania, Canarium, Livistona, Pandanus and Terminalia), of plants available across the southern dispersal arc continue into Australia ${ }^{38,39}$. Therefore, the expenditure of labour in the preparation of a range of recognised plant foods could have ensured reliable access to fats, proteins and carbohydrates required to successfully move into the region.

The evidence for a broad plant food diet at Madjedbebe 65-53 kya is consistent with later Pleistocene archaeobotanical studies conducted in Island Southeast Asia and Sahul ${ }^{8-12}$, and with evidence for EMH diets in Africa and the Middle East ${ }^{4-6}$. As such, it indicates that plant exploitation was a fundamental aspect of EMH diets globally. Culturally transmitted botanical knowledge, and the cognitive ability to perform multi-step and intensive processing sequences likely contributed to the adaptability and flexibility required by EMH populations to traverse continents and colonise new environments around the world.

\section{Methods}

Archaeobotanical analysis. Two $1 \times 1 \mathrm{~m}^{2}$ columns (C3/1-27 and C2/28-57; C6/ 1-15 and C5/16-72) of excavated sediment and all hearths and other features identified during excavation were collected in their entirety for flotation (Supplementary Fig. 2c). A hundred percent of the sediment from these contexts underwent flotation, using a cascading 'Ankara-style' flotation tank $\mathrm{k}^{40}$.

All Phase 2 contexts in Square C2 (C2/46, C2/45, C2/44, C2/43, C2/42, C2/41, $\mathrm{C} 2 / 40, \mathrm{C} 2 / 39 \mathrm{~A}, \mathrm{C} 2 / 38 \mathrm{~A}, \mathrm{C} 2 / 38, \mathrm{C} 2 / 37 \mathrm{~A}$ and $\mathrm{C} 2 / 37)$ and a preserved hearth in Square C1 (C1/43 A) (Supplementary Fig. 2c) were analysed.

As flotation has been suggested to be less effective at recovering denser macrofossils, especially endocarp fragments ${ }^{41}$, both the lighter fraction, or 'flot', and the heavy residue from these contexts were analysed. All charred fragments $>1$ $\mathrm{mm}$ from both fractions were analysed. The relevant plant macrofossils were sorted from the wood charcoal under low-powered light microscopy.

High-powered light microscopy and scanning electron microscope imaging was used to compare the anatomical and morphological features of the archaeological specimens to modern reference material from the region (see below). The identification of this archaeological material was limited by two things: the size of the modern reference collection; and the degree to which the botanical structures vary by family, genus and species.

No attempt was made to quantify the proportion of the diet contributed by different plants, analysis stopping simply at ubiquity. This is because many of the food plants that constituted the diet of people inhabiting the site at 65-53ka would not have been preserved archaeologically ${ }^{42}$. Indeed, many of the plant foods may have been eaten raw and have, therefore, been less likely to come into contact with fire, or have been processed and/or eaten away from Madjedbebe as a part of a mobile foraging strategy ${ }^{43}$. This difference in preservation, determined by past human behaviour, would have been compounded by differences in the preservation rates and the level of identification possible for different taxa ${ }^{44}$.

Reference collection and ethnobotanical research. The modern reference material was collected by SAF, MN, DjDj and research assistants over several seasons in Kakadu National Park. This was carried out with the permission of the Mirarr people, Gundjeihmi Aboriginal Corporation, Parks Australia and the Australian Government (Permit to carry out Scientific Research in a Commonwealth Reserve Permit No. RK870 and RK909; Access to Biological Resources in a Commonwealth Area for Non-Commercial Purposes Permit No. AU-COM2015287, AU-COM2017-339, AU-COM2018-391). Alongside the production of a modern reference collection, ethnobotanical research was also undertaken with $\mathrm{MN}$ and $\mathrm{DjDj}$, to define the material signature of plant exploitation practices in western Arnhem Land. Plants were identified in the field by MN and $\mathrm{Dj} D \mathrm{Dj}$, and these identifications were then verified and furthered by the Northern Territory Herbarium.

Plant samples are housed in the University of Queensland Archaeobotanical Reference Collection, preserved dried, charred and in spirits. Following Hather $2000^{34}$, where underground storage organs, stems and roots were part of the sample, stained thin-sections were produced (using a modified version of the method outlined by Johansen $1940^{45}$ ). This allowed for the anatomical structure of these plant parts to be understood prior to their transformation through charring.

Reporting summary. Further information on research design is available in the Nature Research Reporting Summary linked to this article.

\section{Data availability}

All elements necessary to allow interpretation and replication of results, including full datasets and detailed archaeobotanical identification proofs are provided in the Supplementary Information. Data and R code for Supplementary Fig. 1 are online at https://doi.org/10.17605/OSF.IO/YDUZP46. Archaeobotanical material analysed in this study will be kept in the Archaeology Laboratories of the University of Queensland until 2021. It will then be deposited in a Gundjeihmi Aboriginal Corporation keeping place. The material will be publicly accessible upon request with permission from Gundjeihmi Aboriginal Corporation (gundjeihmi@mirarr.net) and the corresponding authors. The language, images and information contained in this publication includes reference to Indigenous knowledge including traditional knowledge, traditional cultural expression and references to biological resources (plants and animals) of the Mirarr people. The source Indigenous knowledge is considered "Confidential Information"; traditional law and custom applies to it and the Mirarr people assert ownership over it. Any Mirarr related language, images and information are published with the consent of Gundjeihmi Aboriginal Corporation as the representative of the Mirarr people for the purposes of education and specifically for use only in the context of this published work. Please 
contact Gundjeihmi Aboriginal Corporation to request permission to refer to any Indigenous knowledge in this publication.

Received: 5 March 2019; Accepted: 29 January 2020;

Published online: 17 February 2020

\section{References}

1. Jones, M. in The Evolution of Hominin Diets: Integrating approaches to the study of Palaeolithic subsistence (eds Hublin, J.-J. \& Richards, M. P.) 171-180 (Springer, 2009).

2. Flannery, K. V. in The Domestication and Exploitation of Plants and Animals (eds Ucko, P. J. \& Dimbleby, G. W.) 73-100 (Duckworth, 1969).

3. Stiner, M. C. Thirty years on the "Broad Spectrum Revolution" and paleolithic demography. Proc. Natl Acad. Sci. USA 98, 6993-6996 (2001).

4. Henry, A. G., Brooks, A. S. \& Piperno, D. R. Plant foods and the dietary ecology of Neanderthals and early modern humans. J. Hum. Evol. 69, 44-54 (2014).

5. Larbey, C., Mentzer, S. M., Ligouis, B., Wurz, S. \& Jones, M. K. Cooked starchy food in hearths ca. 120 kya and 65 kya (MIS 5e and MIS 4) from Klasies River Cave, South Africa. J. Hum. Evol. 131, 210-227 (2019).

6. Mercader, J. Mozambican grass seed consumption during the Middle Stone Age. Science 326, 1680-1683 (2009).

7. Wadley, L., Backwell, L., d'Errico, F. \& Sievers C. Cooked starchy rhizomes in Africa 170 thousand years ago. Science 367 87-91 (2020).

8. Barker, G. et al. The 'human revolution' in lowland tropical Southeast Asia: the antiquity and behavior of anatomically modern humans at Niah Cave (Sarawak, Borneo). J. Hum. Evol. 52, 243-261 (2007).

9. Barton, H. The case for rainforest foragers: the starch record at Niah Cave, Sarawak. Asian Perspect. 44, 56-72 (2005).

10. Barton, H. \& Paz, V. in Rethinking Agriculture: Archaeological and ethnoarchaeological perspectives (eds Denham, T. P., Iriarte, J. \& Vrydaghs, L.) 50-77 (Left Coast Press, 2007).

11. Fairbairn, A. S., Hope, G. S. \& Summerhayes, G. R. Pleistocene occupation of New Guinea's highland and subalpine environments. World Archaeol. 38, 371-386 (2006).

12. Summerhayes, G. R. et al. Human adaptation and plant use in highland New Guinea 49,000 to 44,000 years ago. Science 330, 78-81 (2010).

13. Clarkson, C. et al. Human occupation of northern Australia by 65,000 years ago. Nature 547, 306-310 (2017).

14. Langley, M. C., Clarkson, C. \& Ulm, S. From small holes to grand narratives: the impact of taphonomy and sample size on the modernity debate in Australia and New Guinea. J. Hum. Evol. 61, 197-208 (2011).

15. Mellars, $\mathrm{P}$. The impossible coincidence. A single-species model for the origins of modern human behavior in Europe. Evol. Anthropol. 14, 12-27 (2005).

16. Groucutt, H. S. et al. Rethinking the dispersal of Homo sapiens out of Africa. Evol. Anthropol. 24, 149-164 (2015).

17. Mellars, P., Gori, K. C., Carr, M., Soares, P. A. \& Richards, M. B. Genetic and archaeological perspectives on the initial modern human colonization of southern Asia. Proc. Natl Acad. Sci. USA 110, 10699-10704 (2013).

18. O'Connell, J. F. \& Allen, J. The restaurant at the end of the universe: modelling the colonisation of Sahul. Aust. Archaeol. 74, 5-17 (2012).

19. Boivin, N. L. et al. Ecological consequences of human niche construction: examining long-term anthropogenic shaping of global species distributions Proc. Natl Acad. Sci. USA 113, 6388-6396 (2016).

20. Roberts, P. \& Stewart, B. A. Defining the 'generalist specialist' niche for Pleistocene Homo sapiens. Nat. Hum. Behav. 2, 542-550 (2018).

21. Roberts, P. et al. Fruits of the forest: Human stable isotope ecology and rainforest adaptations in Late Pleistocene and Holocene (approximately 36 to 3ka) Sri Lanka. J. Hum. Evol. 106, 102-118 (2017).

22. Wedage, O. et al. Specialized rainforest hunting by Homo sapiens $\sim 45,000$ years ago. Nat. Commun. 10, 739 (2019).

23. Blinkhorn, J., Achyuthan, H., Ditchfield, P. \& Petraglia, M. Palaeoenvironmental dynamics and Palaeolithic occupation at Katoati, Thar Desert, India. Quat. Res. 87, 298-313 (2017).

24. Groucutt, H. S. et al. Homo sapiens in Arabia by 85,000 years ago. Nat. Ecol. Evol. 2, 800-809 (2018).

25. Fullagar, R., Field, J., Denham, T. \& Lentfer, C. Early and mid Holocene tooluse and processing of taro (Colocasia esculenta), yam (Dioscorea sp.) and other plants at Kuk Swamp in the highlands of Papua New Guinea. J. Archaeol. Sci. 33, 595-614 (2006).

26. Clarkson, C. et al. Reply to comments on Clarkson et al. (2017) 'Human occupation of northern Australia by 65,000 years ago'. Aust. Archaeol. 84, 84-89 (2018).

27. Wood, R. Comments on the chronology of Madjedbebe. Aust. Archaeol. 83, 172-174 (2017).

28. Specht, R. L. in Australian Vegetation (ed Groves, R. H.) 321-344 (Cambridge University Press, 1994).
29. Northern Territory Government Flora NT: Northern Territory flora online, http://eflora.nt.gov.au/home (2013).

30. Fox, G. \& Garde, M. in An-me Arri-ngun, The Food We Eat: Traditional plant foods of the Kundjeyhmi people of Kakadu National Park. (Gundjeihmi Aboriginal Corporation, 2018).

31. Meehan, B., Gaffey, P. \& Jones, R. in Readings in Material Culture Vol. 9 Occasional papers in anthropology (ed Lauer, P. K.) 73-96 (Anthropology Museum, University of Queensland, 1978).

32. Leichhardt, L. in Journal of an Overland Expedition in Australia, from Moreton Bay to Port Essington, a Distance of Upwards of 3000 Miles, During the Years 1844-1845. (T. \& W. Boone, 1847).

33. Low, T. in Wild Food Plants of Australia. (Angus \& Robertson Publishing, 1991).

34. Hather, J. G. in Archaeological Parenchyma. (Archetype Publications, 2000).

35. Russell-Smith, J. et al. Aboriginal resource utilization and fire management practice in Western Arnhem Land, monsoonal northern Australia: Notes for prehistory, lessons for the future. Hum. Ecol. 25, 159-195 (1997).

36. Fullagar, R. \& Field, J. Pleistocene seed-grinding implements from the Australian arid zone. Antiq 71, 300-307 (1997)

37. Fullagar, R. et al. Evidence for Pleistocene seed grinding at Lake Mungo, south-eastern Australia. Archaeol. Oc 50, 3-19 (2015).

38. van Welzen, P. C., Parnell, J. A. N. \& Ferry Silk, J. W. Wallace's Line and plant distributions: Two or three phytogeographical areas and where to group Java? Biol. J. Linn. Soc. 103, 531-545 (2011).

39. Crisp, M. D., Isagi, Y., Kato, Y., Cook, L. G. \& Bowman, D. M. Livistona palms in Australia: ancient relics or opportunistic immigrants? Mol. Phylogenet. Evol. 54, 512-523 (2010)

40. Nesbitt, M. Plants and People in Ancient Anatolia. Biblic. Archaeol. 58, 68-81 (1995).

41. Hageman, J. B. \& Goldstein, D. J. An integrated assessment of archaeobotanical recovery methods in the Neotropical rainforest of northern Belize: flotation and dry screening. J. Archaeol. Sci. 36 2841-2852 (2009).

42. Hillman, G. C. in Foraging and Farming: The evolution of plant exploitation (eds Harris, D. R. \& Hillman, G. D.) Ch. 13, 207-239 (Unwin Hyman, 1989).

43. Mcarthur, M. in Anthropology and Nutrition (ed. Mountford, C. P.) 2, 90-135 (Melbourne University Press, Melbourne, 1960)

44. Wright, P. Preservation or destruction of plant remains by carbonization? J. Archaeol. Sci. 30, 577-583 (2003).

45. Johansen, D. A. Plant Microtechnique. (McGraw Hill, 1940).

46. Marwick, B. \& Florin, S. A. The First Australian Plant Foods at Madjedbebe 65,000-53,000 years ago. https://doi.org/10.17605/OSF.IO/YDUZP (2019).

47. Norman, K. et al. An early colonisation pathway into northwest Australia 70 60,000 years ago. Quat. Sci. Rev. 180, 229-239 (2018).

48. Story, R. in Lands of the Alligator Rivers Area, Northern Territory 89-111 (Commonwealth Scientific and Industrial Research Organization, Australia, 1976).

49. Story, R. in Lands of the Adelaide-Alligator Area, Northern Territory Land Research Series 114-130 (Commonwealth Scientific and Industrial Research Organization, Australia, 1969)

\section{Acknowledgements}

The archaeobotanical and ethnobotanical research in this project was funded by a Wenner Gren Dissertation Fieldwork Grant (9260), an Australian Institute of Nuclear Science and Engineering Postgraduate Research Award (11877), a Dan David Scholarship and an Australian Postgraduate Award awarded to S.A.F. The initial fieldwork and excavation of Madjedbebe was funded by an Australian Research Council grant (DP110102864) obtained by C.C., B.M., R.F., M.S. and L.W. The authors are grateful to the custodians of Madjedbebe, the Mirarr Senior Traditional Owners (Yvonne Margarula and $\mathrm{MN}$ ) and our research partner, the Gundjeihmi Aboriginal Corporation, for permission to carry out this research and publish this paper. We are also grateful to Justin O'Brien and David Vadiveloo for assistance in the field. We thank Dr Xavier Carah for implementing the archaeobotanical recovery program at Madjedbebe and for his assistance alongside Elspeth Hayes, Kasih Norman, Ashleigh Rogers, Makayla Harding and Kate Connell in the collection of plants and ethnobotanical data. This research was completed in part in Kakadu National Park under Permit No. RK870, RK909; however, the findings and views expressed are those of the authors and do not necessarily represent the views of Parks Australia, the Director of National Parks or the Australian Government. The authors acknowledge the assistance of the staff at Parks Australia, the Northern Territory Herbarium, and the University of Queensland's Archaeology, School of Earth Sciences, and Centre for Microscopy and Microanalysis Laboratories (especially Rachel Price, Linda Northdurft and Ian Cowie). We also thank the student volunteers from the University of Queensland for helping sort the heavy residue. Finally, the authors thank Quan Hua, Rachel Wood, Zenobia Jacobs, Elspeth Hayes and Alison Crowther for their advice and expert opinion during the drafting process.

\section{Author contributions}

S.A.F. and A.F. conducted the archaeobotanical research. S.A.F., M.N. and Dj.Dj. conducted the ethnobotanical research and modern reference collection. S.A.F., A.F. and C.C. wrote the main text. M.N. and Dj.Dj. provided cultural knowledge and assisted in 
the interpretation of the findings. S.A.F., B.M., C.C. and A.F. created the figures. C.C., R.F., B.M., M.S. and L.W. obtained the funding for and conducted the excavations.

\section{Competing interests}

The authors declare no competing interests.

\section{Additional information}

Supplementary information is available for this paper at https://doi.org/10.1038/s41467 020-14723-0.

Correspondence and requests for materials should be addressed to S.A.F. or C.C.

Peer review information Nature Communications thanks Tim Denham, Anne Ford and Juan José García-Granero for their contribution to the peer review of this work. Peer reviewer reports are available.

Reprints and permission information is available at http://www.nature.com/reprints
Publisher's note Springer Nature remains neutral with regard to jurisdictional claims in published maps and institutional affiliations.

(c) (i) Open Access This article is licensed under a Creative Commons Attribution 4.0 International License, which permits use, sharing, adaptation, distribution and reproduction in any medium or format, as long as you give appropriate credit to the original author(s) and the source, provide a link to the Creative Commons license, and indicate if changes were made. The images or other third party material in this article are included in the article's Creative Commons license, unless indicated otherwise in a credit line to the material. If material is not included in the article's Creative Commons license and your intended use is not permitted by statutory regulation or exceeds the permitted use, you will need to obtain permission directly from the copyright holder. To view a copy of this license, visit http://creativecommons.org/ licenses/by/4.0/.

(C) The Author(s) 2020 